\title{
Proper Communication Styles in Educational Setting from Lecturers' Perspectives
}

\author{
Balen M. Muhammed Sdeeq ${ }^{1 a}$, Evie Farida Sulaiman ${ }^{1, b}$, Chnar Zrar Hamad ${ }^{1, c}$, \& Zhwan Dalshad Abdullah ${ }^{1, d^{d *}}$, \\ 1Department of Clinical Psychology, Faculty of Science and Health, Koya University, Koya KOY45, Kurdistan Region - \\ F.R. Iraq; Faculty of Education, Tishik International University, Erbil-Iraq \\ a balen.muhammad@koyauniversity.org; b evie.farida@tiu.edu.iq; c chnar.zrar@koyauniversity.org; \\ d zhwan.dalshad@koyauniversity.org; \\ *Corresponding Author: zhwan.dalshad@koyauniversity.org | Phone Number: +9647501184542
}

Received: 14 Desember 2020

Revised: 15 January 2021

Accepted: 22 February 2021

\begin{abstract}
This study aims to find out the underlying factors of proper communication styles in educational settings from lecturers' perspectives. It also tries to find out if there is any significant difference between male and female lecturers' perspectives towards proper communication styles, and attempts to determine if there are differences between the private and public universities. Analyzing the data from self-developed questionnaire, yielded four factors; namely (listening, oral, writing, and body language) were derived from the varimax rotated matrix. The results revealed a statistically significant difference between the private and public universities lecturers' perspectives towards proper communication. While, no statistically significant difference was found between male and female lecturers in their perspective towards listening, oral, and writing proper communication. The only difference found was in body language communication and it was in favor of female lecturers. The findings of this study will contribute in understanding factors of proper communication styles in educational setting.
\end{abstract}

Keywords: Proper communication; Perspective; Oral communication; Listening communication; Body language communication; Writing communication

\section{Introduction}

Communication style means a group of speech features of an individual in the act of communication. Style is specific methods of receiving the message, personal methods of interpreting the messages; and expressing the response and feedback (Duta et al., 2015). Norton (1975) defines a communication style as "the method a person uses verbal and nonverbal communicative acts to indicate how others should interpret a message. Novinger (2001) also has stated that any act is considered as a type of $u$ communication, as it occurs in a social context. Based on Huble y's (1993) opinion, at any level of communication process things may go wrong, which makes the communication less effective. For example, the senders may not express what they want to say clearly; or the receivers may not understand the words the senders use. Many studies paid attention to how teachers communicate properly with the students inside class with the use of their tone of voice and bcdy language (Prozesky, 2000). Nevertheless, the communication between teachers and students is one of the main areas in teaching process, and it should be in a respective manner. For that matter, many studies have addressed the essential of teacher-student relationship in pr euniversity settings (Roorda et al., 201 1). According to Rowicki, and Mark (1999), communication is the heart of education which is a two-way process.

However, in this current study the purposes and research questions are presented with a detailed description of the study's methods. Results are discussed in terms of participants' perspectives, dimensions assessing the proper communication styles, and the difference between private and government universities. Last, practical and theoretical implications of the study, as well as future research, are considered. For the personality of the young people, the communication skills are essentially crucial (Pânişoarăa et al., 2015). However, studies on lecturer-student relationships at higher education settings are rare. One reason could be lack of a clear theoretical conceptual framework (Hagenauer \& Volet, 2014).

We usually communicate in a variety way, either through oral communication, or listening, body language, and the written words. According to McKay et al. (2009), oral communication style (OCS) refers to spoken words and their meanings and the message that is intended or implied by the spoken words. The 
ability to communicate orally is a fundamental competency for students in university, in addition, the development of sufficient communication skills are vital for success in future career (Al-Nouh et al., 2015). A lecturer's perception of a student's behavior may be influenced by some factors, such as interactions between the student and teacher, and general student performance (Murphy, 2007).

Moreover, the use of email as a means of workplace communication plays an effective role in information transmissions which deal with every day work requirements (Waldvogel, 2007). Specialists and academicians showed raising concerns about ethical problems in the use of the information communication technology (Harncharnchai \& Inplao, 2015), and proper communication through emails has become a topic in many learning areas (Murphy \& Matas, 2006). Studies showed that students use appropriate communication strategies in their academic setting to decrease the gaps between them and their teachers (Faiz \& Suhaila, 2013). Whereas, other studies mentioned that there are many students who are not knowledgeable regarding the use of e-mail effectively or manage the interpersonal dynamics through email communication (Murphy \& Matas, 2006). Likewise, Merdian and Warrior (2015) Merdian and Warrior (2015) stated that although the researches showed that digital communication have changed the ways how teachers and learners communicate for academic purposes, but also showed some shortcomings in the implementation of these tools.

However, to determine what is proper and what is not, is related to many factors such as specific cultures and gender. That is, what might be considered proper method of communication, whether written, oral or nonverbal, in a culture might be improper method in another culture. Merchant (2012) stated that males and females are different in the way they communicate and influence others. As explained by Leaper (1991), males and females use language communication for different reasons, women use language for enhancing social relations also to be more expressive, tentative and polite in conversations, while men use communication to practice power and dominance and also men are more dominant and assertive.

Bowles (2008) conducted a study on profiling year level and gender differences in adolescent communication styles. The findings showed that females were more withdrawing, concession and less confusion focused than males. The findings of this current study addressing the issues of proper communication style might be helpful in educational setting in terms of teaching process. Having positive interactions and relationships between lecturers and students have positive effects on the teachers themselves. When teachers feel respected by their students, a sense of belonging to their institutions or universities will grow. This will also influence the teaching process. Roorda et al. (2011) have found that teacher-student relationship affects both students' achievement and involvement. Thus, this present study examines the underlying dimensions of proper communication styles, and determines the difference between private and government university lecturers in their perspectives towards proper communication styles. This study also tries to determine the difference between male and female lecturers' perspectives towards proper communication styles.

This study attempts to answer the following research questions:

RQ1: What are the underlying dimensions of proper communication styles?.

RQ2: Is there any significant difference between male and female lecturers' perspectives towards proper communication styles?.

RQ3: Is there any significant difference between universities lecturers' perspectives towards proper communication styles from both private and government universities?.

\section{Materials and Methods}

\subsection{Participants}

The participants of this study were selected based on convenient sampling technique. Lecturers from four different private and government universities served as participants of this study, including Koya University (KU), Salahaddin University (SU), Cihan University (CU), and Lebanese French University (LFU). Although three hundred 300 participants took part in this study, but the usable sample consisted of 268 participants. Among them, 81 were female and 187 were male.

\subsection{Measurement}

This study method was quantitative approach with a survey design. The questionnaire was developed by the researchers so as to examine the underlying factors of proper communication styles. The study measures were answered using a five-point response scale ranging from 1 (never) to 5 (always), the specialists and experts have validated the measure. The instrument was pilot tested on a broad sample $(n=190)$. To decide the number of components for each factor, principal component analyses (PCA) was conducted. Consisting forty items and 4 hypothesized dimensions, the first dimension represents the students' body language communication style (BLCS), which is related to their appropriate facial expression, gesture, body posture, 
and attendance behavior, in and outside classes while communicating with their teachers.

The second was geared towards measuring students' listening communication style (LCS), which is describing how skillful they are in listening when they communicate with their teachers, by paying attention, without interruption, receiving and responding to spoken/unspoken messages. The third dimension concerned the oral communication style (OCS) which is related to student's ability to hold a discussion and relevant conversation with their teachers in a respectful manner, by accepting the critical feedbacks, admitting their mistakes and the ability to complaint their teachers respectfully. The fourth dimension represents students' written communication style (WCS) through technology and internet in order to carefully tempering the content of formality, avoiding the use of jargon, and choosing the convenient time to send the messages.

After conducting the PCA exploratory within each block, reliability testing and a careful examination of the correlations, items were deleted and modified. Thus, 23 items were deleted from the instrument and only 17 items were remained. By calculating Coefficient Alpha, reliability was obtained, and to provide further evidence of construct validity and to illustrate the factorial structure of the instrument, a factor analysis was performed.

\section{Results and Discussions}

Principal component analysis was applied to examine the construct of proper communication styles, according to the data collected from the participants $(n=268)$ at public and private universities. The analysis confined to four dimensions, in Table 1 the Kaier-Meyer-Olkin measure of sampling adequacy among the variables was high (.841) which is well above the recommended threshold of (.6) (Kaiser, 1974) and the Bartlett's Test of Sphericity (941.797) reached statistical significance $(p=0.000)$, indicating that the correlations were sufficiently large. The varimax rotation method was applied to the relevant data, to obtain sufficient factor solution. The items to be retained were selected on the basis of the following criteria: the solution was constrained using the criterion of eigenvalue $\geq 1.0$ (Fabrigar et al., 1999) and meeting the criterion of factor loading generally not less than (.34) on the defining component (Hair et al., 1998).

Table 1. KMO and Bartlett's Test

\begin{tabular}{llr}
\hline \multicolumn{2}{l}{ Kaiser-Meyer-Olkin Measure of Sampling Adequacy. } & .841 \\
\hline \multirow{3}{*}{ Bartlett's Test of Sphericity } & Approx. Chi-Square & 941.797 \\
\cline { 2 - 3 } & Df & 136 \\
\cline { 2 - 4 } & Sig. & .000 \\
\hline
\end{tabular}

The analysis confined to four components has met the above criteria that explained a total of (56.7 \%) of the variance. The variance of the first dimension was $(21.5 \%)$, the second $(14.2 \%)$, the third was $(10.7 \%)$ and the last was $(10.2 \%)$. The largest eigenvalue was (4.48) for the first dimension, while the other subsequent eigenvalues were (1.59), and (1.41), Table 2.

Table 2 Total Variance Explained

\begin{tabular}{ccccccc}
\hline \multirow{2}{*}{ Component } & \multicolumn{2}{l}{ Initial Eigenvalues } & & \multicolumn{3}{c}{ Rotation Sums of Squared Loadings } \\
\cline { 2 - 7 } & Total & \% of Variance & Cumulative $\%$ & Total & \% of Variance & Cumulative \% \\
\hline 1 & 4.683 & 27.550 & 27.550 & 3.657 & 21.513 & 21.513 \\
\hline 2 & 2.393 & 14.075 & 41.625 & 2.419 & 14.229 & 35.743 \\
\hline 3 & 1.488 & 8.751 & 50.376 & 1.833 & 10.781 & 46.524 \\
\hline \multirow{2}{*}{4} & 1.088 & 6.402 & 56.778 & 1.743 & 10.255 & 56.778 \\
\hline
\end{tabular}

According to Table 3, the analysis extracted four factor solutions, and the 17 items measured four underlying dimensions. The results suggest the existence of four common elements of the proper communication styles namely BLCS, LCS, OCS, and WCS. The empirical grouping of the items loaded on this factor reasons that the high scores on these dimensions imply that the proper communication styles are highly correlated with the BLCS, LCS, OCS, and WCS. These significant 17-items loading on the four components are represented as being initially hypothesized as a proper communication style.

In order to estimate the reliability for the four dimensions of the proper communication styles, Cronbach's alpha formula was used; see Table 3. The internal consistency indices for this scale were (0.58) for BLCS, (0.62) for OCS, (0.88) for LCS, and (0.76) for WCS. The overall Cronbach's alpha for this scale was $(0.85)$. The varimax rotation indicates that four dimensions of the proper communication styles were moderately correlated. 
Table 3. Loading for four factor rotated solution of proper communication styles and the alpha coefficient

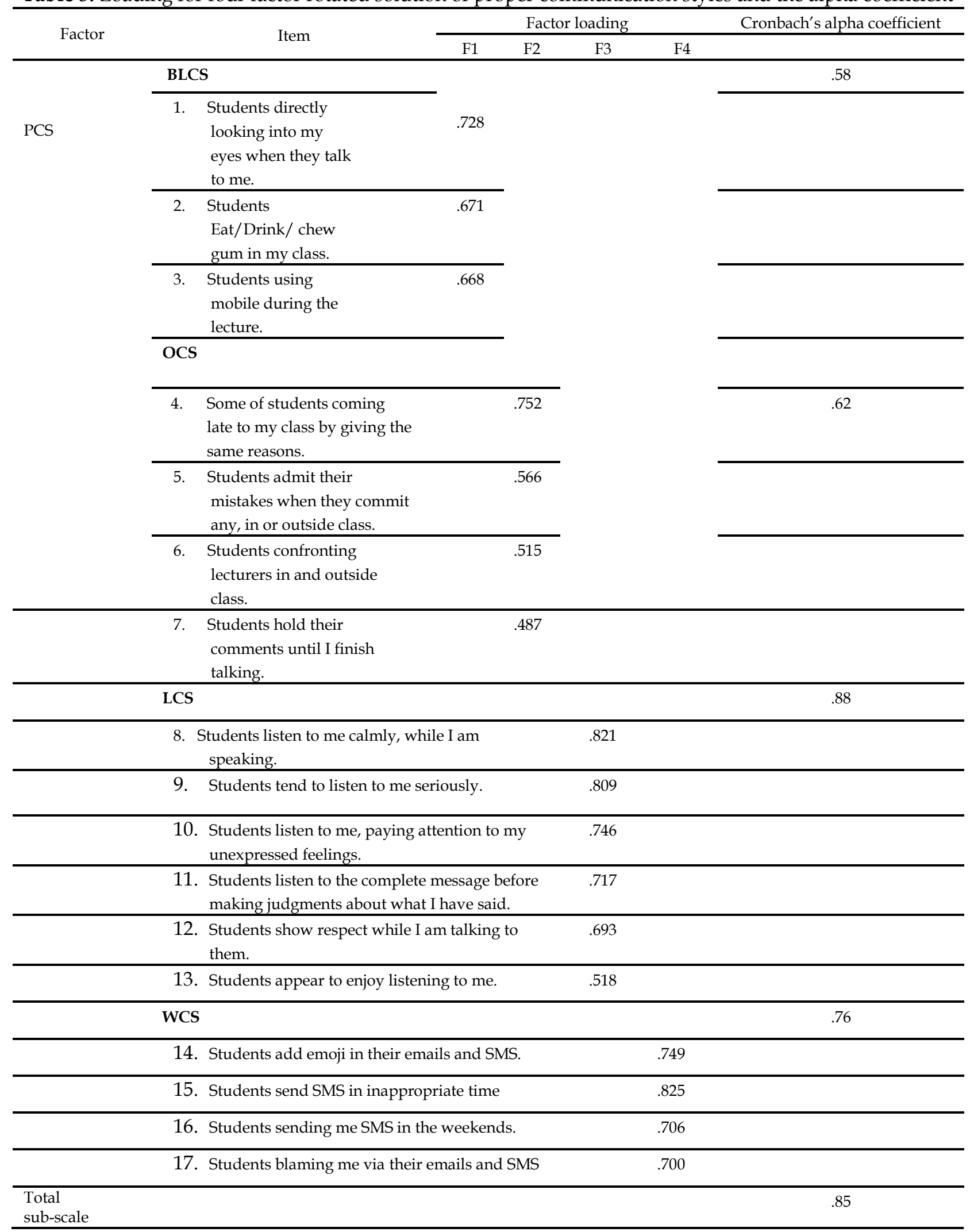

To determine if there is any significant difference between male and female lecturers' perspectives towards proper communication styles, the independent sample t.test was applied. The findings in Table 4 show that there is no statistically significant difference found between male $(M=22.51, S D=4.77)$ and female lecturers $(\mathrm{M}=23.33, \mathrm{SD}=4.75) \mathrm{t}(26)=-1.27, \mathrm{p}=0.2$ in their perspective towards LCS scores. Likewise, no statistically significant difference found between male $(M=15.77, S D=2.88)$ and female lecturers $(M=16.15, S D=3.31)$ $\mathrm{t}(24)=-.90, \mathrm{p}=0.2$ in their perspective towards OCS, and WCS; male $(\mathrm{M}=22.51, \mathrm{SD}=4.77)$ and female lecturers $(\mathrm{M}=23.33, \mathrm{SD}=4.75) \mathrm{t}(26)=-1.27, \mathrm{p}=0.3$, the difference between the two groups' means was not 
significant $(p>0.05)$. The only difference found was in BLCS for male $(M=11.53, S D=1.98)$ and female lecturers $(M=12.20, S D=1.78) t(16)=-2.71, p=0.007$ and it was in favor of female lecturers. This finding was consistent with Bowles (2008) and this may suggest that the female lecturers are more sensitive to the interests and needs of their students and more understanding in comparison with male lecturers, in return students communicating with their female lecturers in more appropriate way.

Table 4 The t-Test for Differences in External Factor proper communication style between Female and Male Lecturer.

\begin{tabular}{|c|c|c|c|c|c|c|c|}
\hline Variable & Group & $\mathrm{N}$ & $\mathrm{M}$ & SD & $\mathrm{T}$ & $\mathrm{df}$ & Sig \\
\hline \multirow[t]{2}{*}{ LCS } & Male & 182 & 22.51 & 4.77 & 1.27 & 26 & 0.20 \\
\hline & Female & 80 & 23.33 & & & & \\
\hline \multirow[t]{2}{*}{ OCS } & Male & 175 & 15.04 & 2.88 & -.90 & 24 & 0.25 \\
\hline & Female & 71 & 15.48 & & & & \\
\hline \multirow[t]{2}{*}{ WCS } & Male & 170 & 15.77 & 4.77 & -1.27 & 26 & 0.36 \\
\hline & Female & 72 & 16.15 & & & & \\
\hline \multirow[t]{2}{*}{ BLCS } & Male & 182 & 11.53 & 1.78 & -2.71 & 16 & 0.007 \\
\hline & Female & 81 & 12.20 & & & & \\
\hline
\end{tabular}

One-way analysis of variance (ANOVA) was subsequently performed to compare the differences between universities lecturers' perspective towards proper communication styles (OCS, LCS, WCS, and BLCS) from both private universities (Cihan, and Lebanese French) and public universities (Koya, and Salahaddin). As shown in Table 5, the results suggest that there was a significant deference in LCS, F(3,258) $=8.369, \mathrm{p}=0.00$ and BLCS, $\mathrm{F}(3,259)=5.592, \mathrm{p}=0.00$, the university lecturers differ in their perspective. While the OCS, $\mathrm{F}(3$, $242)=2.508, p=n . s$ and $\operatorname{WCS} F(3,238)=2.127, p=n . s$, was not significant, Koya University, Salahaddin University, Cihan University, and Lebanese French University lecturers did not differ on the reported amounts of their perspective.

Table 5. One-way analysis of variance of lecturers' perspective towards proper communication styles

\begin{tabular}{llccccc}
\hline & Source & $\mathrm{df}$ & $\mathrm{ss}$ & $\mathrm{MS}$ & $\mathrm{F}$ & $\mathrm{P}$ \\
\hline OCS & Between Groups & 3 & 56.085 & 18.696 & 2.508 & .060 \\
\hline & Within Groups & 242 & 1804.081 & 7.455 & & \\
\hline & Total & 245 & 1860.167 & & & \\
\hline LCS & Between Groups & 3 & 527.466 & & & .000 \\
\hline & Within Groups & 258 & 5420.385 & 175.822 & 8.369 & .098 \\
\hline & Total & 261 & 5947.851 & 21.009 & & \\
\hline WCS & Between Groups & 3 & 57.294 & 19.098 & 2.127 & \\
\hline & Within Groups & 238 & 2137.466 & 8.981 & & \\
\hline & Total & 241 & 2194.760 & & & \\
\hline BLCS & Between Groups & & & & \\
\hline & Within Groups & 3 & 60.303 & 20.101 & 5.592 & \\
\hline
\end{tabular}

Post hoc tests were conducted and revealed that the mean score of Koya University $(M=21.11, S D=5.112)$ was significantly different than the mean scores of Salahaddin University $(M=23.85, S D=4.411), p=0.00$ in favor of Salahaddin University, and Cihan University $(\mathrm{M}=24.79, \mathrm{SD}=3.378), \mathrm{p}=0.02$ in favor of Cihan University and Lebanese French University $(M=23.96, S D=3.350), p=0.01$ in favor of Lebanese French University in their LCS. In comparison, in terms of BLCS Koya University $(\mathrm{M}=11.18, \mathrm{SD}=2.046)$ was significantly different than the mean scores of Salahaddin University $(M=12.08, S D=1.706), p=0.00$ in favor of Salahaddin University, and Lebanese French University $(M=12.26, S D=2.086), p=0.04$ in favor of Lebanese French University, but did not significantly differ from Cihan University $(M=12.36, S D=1.692) p=$ 0.12. This shows that the communication between lecturers and students at Koya University is not appropriate, this might refer to the weak relationship among organization members, whether between lecturers and students, lecturers and their colleagues, lecturers and administrators. This finding was consistent with (Abdullah \& Jasmi, 2016). 


\section{Conclusions}

The findings of this study provide evidence of the proper communication styles in educational settings which might be helpful in education in terms of teaching process. The findings provide important insights into the interactions and relationships between lecturers and students in an appropriate style to be more effective. When teachers feel respected by their students, a sense of belonging to their institutions or universities will grow. Thus, the effective communication will be constructed if there is a good relationship among organization members, such as students and lecturers, lecturers and their colleagues, administrators and lecturers. Future research to investigate the students' perspective towards lecturers' proper communication styles is recommended.

\section{Acknowledgement}

The authors would like to thanks all the academic staff from Koya; Salahaddin; Cihan; and Lebanese French Universities who participated in this study.

\section{Author's Contributions}

All authors discussed the results and contributed to from the start to final manuscript.

\section{Conflict of Interest:}

The authors declare that they have no competing interests.

\section{References}

Abdullah, M. N., and Jasmi, K. A. (2016). Communication Style towards Student by Excellent Islamic Education Lecturers in Teaching Education Institute of Malaysia. International Journal of Academic Research in Progressive Education and Development 5(3). doi:10.6007/ijarped/v5-i3/2185

Al-Nouh, N. A., Abdul-Kareem, M. M., and Taqi, H. A. (2015). EFL College Students' Perceptions of the Difficulties in Oral Presentation as a Form of Assessment. International Journal of Higher Education 4(1). doi:10.5430/ijhe.v4n1p136

Dixon, T., \& O'Hara, M. (2012). Communication skills. United Kingdom: University of Ulster.

Dow, J. M., Boettcher, C. A., Diego, J. F., Karch, M. E., Karch, A. and Woods, K.M. (2015). Case-based Learning as Pedagogy for Teaching Information Ethics Based on the Driven Sense-Making Methodology. Education for Library and Information Science, 56:141-156. doi:10.12783/issn.23282967/56/2/2

Duta, N., Panisoara, G., \& Panisoara, I. (2015). The Effective Communication in Teaching. Diagnostic Study Regarding the Academic Learning Motivation to Students. Procedia - Social and Behavioral Sciences, 186, 1007-1012. doi:10.1016/j.sbspro.2015.04.064

Faiz, H. \& Suhaila, N. (2013). Use of Greetings in SMS Messages from Students toLecturers at a Malaysian University. International Journal of Social Science and Humanity, 3(2):125-128. doi: 10.7763/IJSSH.2013.V3.210.

Geçer, A. (2013). Lecturer- Student Communication in Blended Learning Environments. Journal Educational Sciences: Theory \& Practice, 13(1):362-367. https:/ files.eric.ed.gov/fulltext/EJ1016744.pdf

Harncharnchai, A.\& Inplao, K. 2015. Information Ethics and Behaviors of Upper Secondary Students Regarding the Use of Computers and the Internet. Journal of Information Ethics, 24(1): 98-116. https://search.proquest.com/openview/8ee7fbed8f5dc9f79b17c5aab76815da/1?pqorigsite $=$ gscholar\&cbl $=2035668$

Jeynes, W. H. (2017). Effects of Family Educational Cultures on Student Success at School: Directions for Leadership. Studies in Educational Leadership, 23(1): 311-328. doi:10.1007/978-3-319-50980-8_14

Leaper. C. (1991). Influence and involvement in children's discourse: Age, gender, and Gender Differences in Leadership 60 partner effects. Child Development 62:797-811. https://doi.org/10.1111/j.14678624.1991.tb01570.x

Majid, N. A. (2012). Keperluan Kemahiran Komunikasi Dalam proses pengajiran dan pembelajaran dalam kalangan guru cemerlang. Prociding Seminar Penyelidikan Pendidikan IPG (pp.1-6).

McKay, M., Davis, \& Fanning, p. (2009). Message:the communication skills book. Okland, CA: New Hrbinger publications.

Merchant, K. (2012). How men and women differ: Gender differences in communication styles, influence tactics, and leadership styles. Clare Mount College Senior Theses, Paper 513. Available online: http://scholarship.claremont.edu/cmc_theses/513 
Merdian, Hannah Lena and Warrior, John Kyle. (2015). Effective communication between students and lecturers: improving student-led communication in educational settings. Psychology Teaching Review, 21, (1): 25-43. https:// files.eric.ed.gov/fulltext/EJ1146464.pdf

Murphy, L.A., F., A. (2007). Student Perceptions of Lecturer Classroom Communication Style. Journal in European of Social Sciences, 5(3): 45-60. http://oro.open.ac.uk/53081/2/53081.pdf

Murphy, Margaret and Mike Levy. (2006). Politeness in intercultural email communication: Australian and Korean Perspectives. Journal of Intercultural Communication, 12, http://www.immi.se/intercultural/nr12/murphy.htm.

Pânişoară, G., Sandu, C., Pânişoară, I., \& Duță, N. (2015). Comparative Study Regarding Communication Styles of the Students. Procedia - Social and Behavior Sciences, 186, 202-208. doi:10.1016/j.sbspro.2015.04.066

Sun, R. C., \& Shek, D. T. (2012). Student Classroom Misbehavior: An Exploratory Study Based on Teachers Perceptions. The Scientific World Journal, 1-8. doi:10.1100/2012/208907

Terry Bowles. (2008). Profiling Year Level Gender Differences in Adolescent Communication styles. Australian Educational and Developmental Psychology 25,(1): 70-95. doi: 10.1375/aedp.25.1.70

Waldvogel, J. (2007). Greetings and Closings in Workplace Email. Journal of Computer-Mediated Communication, 12:456-477. https://doi.org/10.1111/j.1083-6101.2007.00333.x

Clancy, T., Stiner, C., \& Koltz, T. (2002). Shadow warriors: Inside the special forces. New York, NY: Putnam.

Austin, J. H. 1998. Zen and the brain: Toward an understanding of meditation and consciousness. Cambridge, MA: MIT Press.

Calarco, M., \& Atterton, P. (2009). Animal philosophy: Essential readings in continental thought. New York, NY: Continuum.

Chen, J. Q. (2003). Intelligence: multiple intelligences. In J. Guthrie Ed.,Encyclopedia of education. New York, NY: Macmillan.

Prozesky DR. (2000). Communication and effective teaching. Community Eye Health, 13(35):44-5.

Hubley J. (1993). Communicating Health: an action guide to health education and health promotion. London and Basingstoke, Macmillan.

Norton, R. W., \& Miller, L. D. (1975). Dyadic perception of communication style. Communication Research, 2(1):50-67. http://dx.doi.org/10.1177/009365027500200103

Novinger, T. (2001). Intercultural communication: Practical guide. Austin, Texas: University of Texas Press. 